\title{
EXAMINATION OF THE ANTIBACTERIAL AND ANTI- FUNGAL PROPERTIES OF FATTY ACIDS AND FATTY ACID METHYL ESTER OBTAINED FROM Nannochloropsis oculata
}

\author{
Z. Chaidir, ${ }^{1, *}$, S. Rahmi ${ }^{1}$, M. Salim ${ }^{1}$, E. Mardiah ${ }^{1}$ and H. Pardi ${ }^{2}$ \\ ${ }^{1}$ Laboratory of Biochemistry, Department of Chemistry, Faculty of Mathematics and Natural \\ Sciences, Andalas University, Padang 25163, Indonesia \\ ${ }^{2}$ Department of Chemistry Education, Faculty of Teacher Training and Education, Raja Ali Haji \\ Maritime University, Senggarang, Tanjungpinang 29100, Indonesia \\ *E-mail: zulkarnainchaidir@sci.unand.ac.id
}

\begin{abstract}
Microalgae are potential producers of lipids that are possibly used as an alternative raw material in biodiesel and drug production. This study, therefore, obtained lipids from the microalgae Nocochloropsis oculata (N. oculata), which was isolated from West Sumatera, and tests were conducted for the antimicrobial and anti-fungal properties of fatty acids and fatty acid methyl esters (FAME) present. Also, the extraction process involved ultrasonication with n-hexane solvent at a ratio of 1: 8 (1 mg dry N.oculata extracted with $8 \mathrm{~mL}$-hexane), and transesterification was performed subsequently with methanol, using $\mathrm{H}_{2} \mathrm{SO}_{4}$ as a catalyst to form fatty acids and FAME, which were evaluated using disc diffusion. Meanwhile, the antimicrobial activity against Staphylococcus aureus (a grampositive bacteria), Escherichia coli (a gram-negative bacteria), and Candida albicans (a fungus) were recorded, subsequently, the fatty acid and FAME concentration used were 100, 200, and $300 \mathrm{mg} / \mathrm{L}$. The results show a relatively higher antibacterial activity in N.oculatafatty acids than FAMEs and no antifungal effect against Candida albicans. Also, gas chromatography-mass spectrometry identified the lipid to mainly consist of palmitic acid, stearic acid, methyl laurate, and methyl stearate.
\end{abstract}

Keywords: Nannochloropsis oculata, Fatty Acid, Fatty Acid Methyl Ester (FAME), Antimicrobial, Anti-fungal.

(c) RASĀYAN. All rights reserved

\section{INTRODUCTION}

Microalgae are microscopic water plants, which serve as sources of animal feed, human food, and nonfood chemicals ${ }^{1}$. They are known to contain numerous bioactive molecules, including lipids that are widely used in the development of antimicrobial compounds. Also, the marine variety has been pioneered several pharmaceutical chemicals, especially those used in anti-cancer agents, cosmetics, enzymes, pigments, antioxidants, long-chain fatty acids, nutritional supplements, and biofuels. Meanwhile, they are also capable of producing secondary metabolites that accumulate in growth media at the end of an exponential period and during the stationary phase. Conversely, some studies suggest the probability to inhibit the growth of harmful bacteria and fungi, although few investigations have been conducted to identify the plausible compounds. This instigated the characterization of possible candidates as the purpose of this research, which includes fatty acids, other organic acids, bromophenol, other phenolic inhibitors, tannins, terpenoids, polysaccharides and other carbohydrates ${ }^{2}$. Microalgal fatty acids and FAME could potentially be antimicrobial ${ }^{3}$.

The microalgae Nocochloropsis oculata ( $N$. oculata) is an easily mass cultured microorganism, which does not cause toxicity or damage to ecosystems, and also demonstrates antibiotic properties. Also, it is also known to contain about $20-30 \%$ lipids, making it an ideal candidate for fatty acids and fatty acid methyl ester (FAME) production, which have an elevated propensity of being used to inhibit bacterial and fungal growth. This study, therefore, investigates the antimicrobial properties of fatty acids and FAME, isolated from microalgae $N$. oculata, obtained from West Sumatera, where coastal waters serve as a rich source ${ }^{4}$.

Rasayan J. Chem., 13(2), 1134-1143(2020)

http://dx.doi.org/10.31788/RJC.2020.1325677 
RASĀYAN J. Chem.

Vol. 13 | No. 2 |1134 - 1143| April - June | 2020

\section{EXPERIMENTAL}

\section{Chemicals, Equipment and Instrumentation}

$N$. oculata microalgae were obtained from the Andalas University Biochemistry laboratory, alongside the n-hexane, methanol, Bold's Basal Medium (BBM), Nutrient Agar Medium (NA), Potato Dextrose Agar Medium (PDA), chloroform, concentrated $\mathrm{H}_{2} \mathrm{SO}_{4}$, boiled seawater, Whatman filter paper No. 1, aquadest, streptomycin sulphate (positive control of bacteria), ketoconazole (positive control of fungi), gramnegative bacteria; Escherichia coli, gram-positive bacteria; Staphylococcus aureaus and the fungus; Candida albicans.

\section{Equipment and Instrumentation}

The tools used included aquarium pumps, hose, analytical balance, UV-Vis Genesys 20 spectrophotometer, 24-watt Visesx fluorescent light, centrifuge, petri dish, inoculation needles, an autoclave, laminar flow cabinet, cotton bud, a light microscope, Sonorex Digitec Bandelin ultrasonicator, separating funnel, micropipette, gas chromatography mass spectrometer (GC-MS), Luxmeter application, and laboratory glass equipment.

\section{Experimental Procedures, Isolation, Extraction, and Observation of microalgae N. oculata}

The microalga, $N$. oculata was cultured on BBM and BBM mixed with seawater 5 . This was further examined in the Biochemistry Laboratory of the Department of Chemistry, Faculty of Mathematics and Natural Sciences, Andalas University, applying $10 \mathrm{~mL}$ samples of the culture on a glass slide under a light microscope, to identify and ensure purity by comparing with the microalgae laboratory sourced stocks. This procedure was repeated for morphological observation.

\section{Preparation of Growth Medium}

Both BBM and BBM were tested with sterile seawater, to select the most suitable growth medium for $N$. oculata, and BBM was chosen based on it being universal. Moreover, the seawater mix was termed marine microalgae, with seawater as its natural habitat, and this selection was conducted for the subsequent growth of the microorganism. Furthermore, BBM consisting of $10 \mathrm{~mL}$ macronutrients (1-6) and $1 \mathrm{~mL}$ of micronutrients (7-10),.was diluted with aquades to make $1 \mathrm{~L}$, then the media was subsequently autoclaved and cooled to room temperature before use. Also, the BBM with seawater solution was made similarly, although aquades was replaced with sterilized sea water ${ }^{5}$, while microalgae $N$. oculata was grown in twenty $100 \mathrm{~mL}$ glass bottles, of which ten composed of $88 \mathrm{~mL}$ plain BBM media and ten of the saltwater type. Therefore, five of each were placed to receive sunlight, and the remaining were restrained under a fluorescent light, at room temperature $\pm 28{ }^{\circ} \mathrm{C}$, and simultaneously aerated using an aquarium pump.

To obtain the microalgae growth curve, absorbance measurements were performed daily, using a UV-Vis spectrophotometer, at a wavelength of $540 \mathrm{~nm}$, up to the point where a decline in absorbance value was obtained ${ }^{6}$. Therefore, the cultures were examined in the Biochemistry Laboratory of the Department of Chemistry, Faculty of Mathematics and Natural Sciences, Andalas University, using $10 \mathrm{~mL}$ samples of culture on a glass slide. These were evaluated under a light microscope, to ensure purity.

Table-1: Bold's Basal Medium (BBM) Freshwater Algae

\begin{tabular}{l|c}
\hline \multicolumn{1}{c|}{ Stocks } & Per $400 \mathrm{~mL}$ \\
\hline (1) $\mathrm{NaNO}_{3}$ & $10.0 \mathrm{~g}$ \\
\hline (2) $\mathrm{MgSO}_{4} \cdot 7 \mathrm{H}_{2} \mathrm{O}$ & $3.0 \mathrm{~g}$ \\
\hline (3) $\mathrm{NaCl}$ & $1.0 \mathrm{~g}$ \\
\hline (4) $\mathrm{K}_{2} \mathrm{HPO}_{4}$ & $3.0 \mathrm{~g}$ \\
\hline (5) $\mathrm{KH}_{2} \mathrm{PO}_{4}$ & $7.0 \mathrm{~g}$ \\
\hline (6) $\mathrm{CaCl}_{2} 2 \mathrm{H}_{2} \mathrm{O}$ & $1.0 \mathrm{~g}$ \\
\hline (7) $\mathrm{Trace} \mathrm{Element} \mathrm{Solution}_{\text {(Autoclave to dissolve): }}$ & \\
\hline
\end{tabular}


RASĀYAN J. Chem.

Vol. 13 | No. 2 |1134 - 1143| April - June | 2020

\begin{tabular}{c|c}
\hline $\mathrm{ZnSO}_{4} 7 \mathrm{H}_{2} \mathrm{O}$ & $8.82 \mathrm{~g}$ \\
\hline $\mathrm{MnCl}_{2} 4 \mathrm{H}_{2} \mathrm{O}$ & $1.44 \mathrm{~g}$ \\
\hline $\mathrm{MnO}_{3}$ & $0.71 \mathrm{~g}$ \\
\hline $\mathrm{CuSO}_{4} 5 \mathrm{H}_{2} \mathrm{O}$ & $1.57 \mathrm{~g}$ \\
\hline $\mathrm{Co}\left(\mathrm{NO}_{3}\right)_{2} 6 \mathrm{H}_{2} \mathrm{O}$ & $0.49 \mathrm{~g}$ \\
\hline (8) $\mathrm{H}_{2} \mathrm{BO}_{3}$ & $11.42 \mathrm{~g}$ \\
\hline (9) $\mathrm{EDTA}$ & $50.00 \mathrm{~g}$ \\
\hline (10) KOH & $31.00 \mathrm{~g}$ \\
\hline (11) $\mathrm{FeSO}_{4} 7 \mathrm{H}_{2} \mathrm{O}$ & $4.98 \mathrm{~g}$ \\
\hline (12) $\mathrm{H}_{2} \mathrm{SO}_{4}$ & $1.0 \mathrm{~mL}$ \\
\hline
\end{tabular}

Medium : Solution 1- 6:10 mL/L each; Solution 7- 10:1 mL/L each; Source

\section{Effect of the Light Source on Microalaga Growth}

Exactly $10 \mathrm{ml}$ of Microalgae $N$. oculata stock solution was grown in $100 \mathrm{~mL}$ medium placed in glass bottles, with a culture volume of $88 \mathrm{~mL}$, and the artificial light source used was 3000 lux spiral neon lights, within a photoperiod of 12 hours light and darkness each. Therefore, the temperature observed during cultivation varied about $\pm 3^{\circ} \mathrm{C}$, due to the heat from the lamp, and then the samples grown under natural sunlight beside a window received indirect light, with intensity influenced by weather conditions. This experiment took place near the equator, and the microalgae growth curve, and the absorbance measurements using UV-Vis spectrophotometer at $540 \mathrm{~nm}$, were taken each day until a decline in the absorbance value was recorded ${ }^{7,8}$.

\section{Cultivation of Pure N. oculata Culture}

A total of $10 \mathrm{ml} \mathrm{N}$. oculata stock solution was cultivated aerobically at $\pm 28^{\circ} \mathrm{C}$, inside the medium chosen, and under sunlight, using an aquarium air pump at the mouth of a glass bottle to aerate the medium. Therefore, each culture was examined closely, to ensure purity, and maintained by gradually adding sufficient medium and pure culture to prevent it from dying out ${ }^{9}$.

\section{Estimation of Growth and Dry Biomass}

At the end of the exponential phase, the dry weight of $N$. oculata biomass in the growth medium was obtained using a standard calibration curve determined from the regression equation of absorbance, as a function of dry weight. Therefore, $10 \mathrm{~mL}$ of microalgae culture was prepared by adding a medium, with the ratio of $0: 10,2: 8,4: 6,6: 4,8: 2$ and 10:0, and Also, absorption was measured at $540 \mathrm{~nm}$, then centrifugation was performed, the supernatant was extracted, and the precipitant dried to a constant weight, and weighed to measure the biomass dry weight. Furthermore, the absorbance value was plotted against the dry weight to make a standard calibration curve ${ }^{10,11}$.

\section{Harvesting of Microalgal Biomass}

The microalgae were harvested at the end of the exponential phase by centrifugation at $3500 \mathrm{rpm}$ for 10 min, then dried at room temperature and stored at $-20^{\circ} \mathrm{C}$.

\section{Lipid Extraction}

Microalgae lipid extraction required the sonication process, then $100 \mathrm{mg}$ dried weight was mixed with 10 $\mathrm{mL}$ of $\mathrm{n}$-hexane, then sonicated for $30 \mathrm{~min}$ at $35 \mathrm{kHz}$. Therefore, the supernatant containing the lipids were separated, and the pellet obtained was again added to n-hexane. This process was repeated for complete extraction, and the supernatant obtained was left at room temperature to evaporate the solvent, thus, leaving the lipid behind. ${ }^{12,14}$

\section{Lipid Transesterification}

Methanol was added to the lipid extract $(1: 6 \mathrm{v} / \mathrm{v})$, as well as 2 drops of $\mathrm{H}_{2} \mathrm{SO}_{4}$ catalyst, and the mixture was heated for $30 \mathrm{~min}$, at $80^{\circ} \mathrm{C}$. Therefore, $4 \mathrm{~mL}$ of distilled water and $4 \mathrm{ml}$ of chloroform were added and subjected to centrifugation, then the chloroform layer was separated and subsequently left at room 
RASĀYAN J. Chem.

Vol. 13 | No. 2 |1134 - 1143| April - June | 2020

temperature for complete chloroform evaporation ${ }^{15}$. Also, the transesterification product (FAME) was analyzed with GC-MS, using an external standard of methyl nonadecanoate.

\section{Preparation of Media for Antimicrobial Assays}

Microbial assay involved the use of nutrient Agar (NA) to grow bacteria, which was prepared by dissolving $2.3 \mathrm{~g}$ of NA powder into $100 \mathrm{~mL}$ of distilled water, heated to a boiling point, then autoclaved. Potato Dextrose Agar (PDA) was applied in the cultivation of fungi, prepared similarly, but using $3.9 \mathrm{~g}$ of PDA powder.

\section{Antimicrobial Activity of Fatty Acids}

NA or PDA sterile medium were poured into separate Petri dishes at room temperature, and a small amount of bacterial suspension was added using an inoculating loop. Furthermore, the microbial suspensions were smeared across the surface of plates, using a cotton bud, a sterile disk of Whatman filter paper No. 1 was immersed into the lipid extract, and diluted with n-hexane to a concentration of 100, 200, or $300 \mathrm{mg} / \mathrm{L}$, which was deposited subsequently added. Also, the positive control for bacteria was streptomycin sulfate, and $10 \mathrm{mg} / \mathrm{L}$ ketoconazole for fungi, while the negative control was $\mathrm{n}$-hexane. Consequently, the Petri dishes were incubated at $37^{\circ} \mathrm{C}$ for 24 hours, and the diameter of the inhibition zone formed around the paper disk was measured ${ }^{15,16}$.

\section{Antimicrobial Activity of Fatty Acid Methyl Esters (FAME)}

NA and PDA sterile medium were poured separately into Petri dishes and allowed to stand at room temperature. These were further inoculated with bacterial or fungal suspensions, using an inoculating loop that was smeared across the plates with a cotton bud, which moistened the entire surface for fatty acid samples. Also, sterile disks of Whatman filter paper No. 1 were soaked in FAME, and diluted with Nhexane up to a concentration of 100,200 , and $300 \mathrm{mg} / \mathrm{L}$, respectively, and subsequently deposited on the plates. Therefore, the Petri dishes were incubated at $37^{\circ} \mathrm{C}$ for 24 hours, and the diameter of the inhibition zone formed around the paper disk was measured ${ }^{15,16}$.

\section{GC-MS Analysis}

The transesterification product (FAME) was analyzed with GC-MS, using methyl nonadecanoate as an external standard.

\section{Microalgae Cell Observation}

\section{RESULTS AND DISCUSSION}

Observing the cells of $N$. Oculata microalgae under a light microscope at a magnification $1000 \mathrm{x}$ revealed the morphological features, as seen in Fig.-1. These microorganisms live in the ocean, although they are also found in fresh and brackish water. Also, the species with green cells are not motile or flagged, also small and spherical, popular for rotifer, and $\operatorname{artemia}^{17}$.

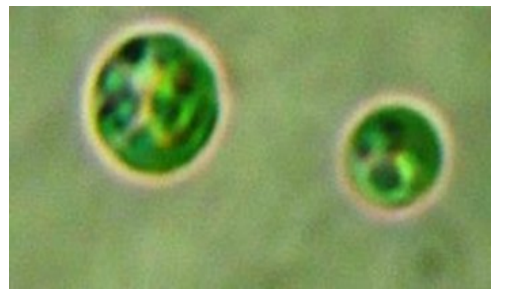

Fig.-1: The Microscopic Images of N. oculata $1000 \mathrm{x}$

\section{Effect of Medium on Microalgae Growth}

According to Karowe et al (2010) ${ }^{17}$ the growth of microalgae is influenced by environmental conditions, among others, the quality and quantity of nutrients (nutrients). Nutrients needed by microalgae consist of micronutrients and macronutrients. Each of these macro and micronutrients has a function in the growth of microalgae. High absorbance values indicate more significant biomass, and a maximum growth curve denotes optimal harvest time. Also, the relative peak size suggests BBM without seawater as the preferable medium for optimized growth, which plateaus after 5 days. Conversely, those prepared in 
RASĀYAN J. Chem.

Vol. 13 | No. 2 |1134 - 1143| April - June | 2020

distilled water mix tend to flourish up to day 15 , where a comparably higher concentration of cells was observed.

Microalgae N. oculata obtains complete nutrients from seawater that, however, growth does not reach its optimum, although the fuel medium was added. The reduced yields observed in the BBM/seawater medium maybe because the $N$. oculata has not adapted to the saline environment of seawater ${ }^{18}$, and that the nutrition is more complete in the distilled water preparations, and values obtained are seen in Fig.-2.

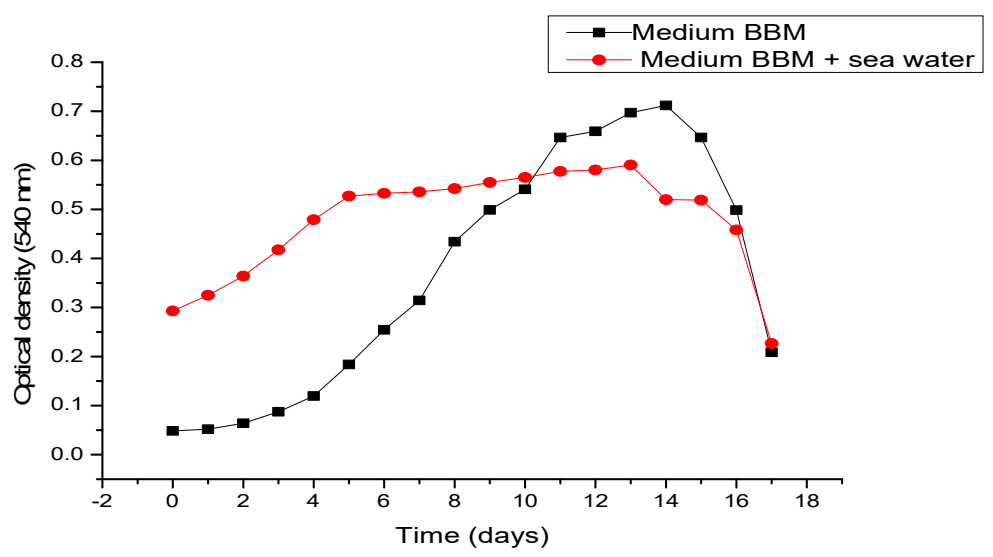

Fig.-2: Growth Curve of $N$. oculata with Different Media

Mixed BBM with seawater shows lower yields, where the highest absorbance value was 0.5905 , but 0.725 for those prepared with distilled water, which maintains the growth better, on the basics of adaptation. Saputro B R et al (2015) conducted a study using a mixture of coconut water with seawater, the results were also not satisfactory. ${ }^{19}$

\section{Effect of Light Source on Microalgae Growth}

The presence of sunlight is known to determine the growth patterns of microalgae that can photosynthesise. This effect is also felt with TL light, with an optimum range of intensity of between $2.000-8.000$ lux. Also, the light-absorbing pigment of green microalgae is chlorophyll, as well as other pigments, including carotenoids and xanthophyl1 ${ }^{20}$.

The light source used was a 24-watt spiral fluorescent, with set intensity 3000 lux, and exposure photoperiod of 12 hours of light and darkness, each, and the selection was based on the optimal biomass and lipid content ${ }^{7}$. Figure- 3 shows that the use of this lamp results in better growth of $N$. oculata than natural sunlight, with the exponential phase starting on the 1st day, and the peak value was obtained on the $6^{\text {th }}$ day, with an absorbance value of 0.83 . Meanwhile, illuminating the culture with sunlight initiated the exponential phase on the 4th day, which peaked on the $11^{\text {th }}$ day, with an absorbance value of 0.65 . Thus, the artificial light source resulted in a superior growth rate because the intensity of light provided is more significant and constant.

Table-2 indicates that the use of neon 3000-watt lamps had the highest OD value on day 9, (0.9295), while the most significant for sunlight occurred on day 13, with a value of 0.697 , because the fluorescent intensity is more constant. Also, the axis X (axis) depicts the day, while the Y-axis (ordinate) contains the values for OD, which was obtained from the measurement results. Fig. 3 clearly shows the speed at which using light reaches the stationary phase on day 9 , and directly lowers the OD value, and similar events occurred with the sunlight treatment, but on day 14 , which was not directly reduced. The data obtained is applied in the cultivation of $N$. oculata microalgae with BBM media, to estimate its optimalbiomass expected to produce fat, which is also used as a raw material for drugs, especially as antibiotics. Furthermore, the produce was hydrolyzed to fatty acids, and FAME, and BBM medium was used to determine the effect of a light source on microalgae growth. Also, the light source was a 24-watt fluorescent spiral lamp, with an intensity of \pm 3000 lux, anda photoperiod of 12 hours for light and 
RASĀYAN J. Chem.

Vol. 13 | No. 2 |1134 - 1143| April - June | 2020

darkness each, and the selection was based on the biomass with comparably higher lipid content. Fig. 3 shows the best irradiation source to be 3000 lux light, with the exponential phase initiated on the first day, and peak value obtained on day 6 , with an absorbance of 0.83 . According to research by Sara P., et al $(2015)^{21}$, light highly influences the resulting biomass, and lipid obtained.

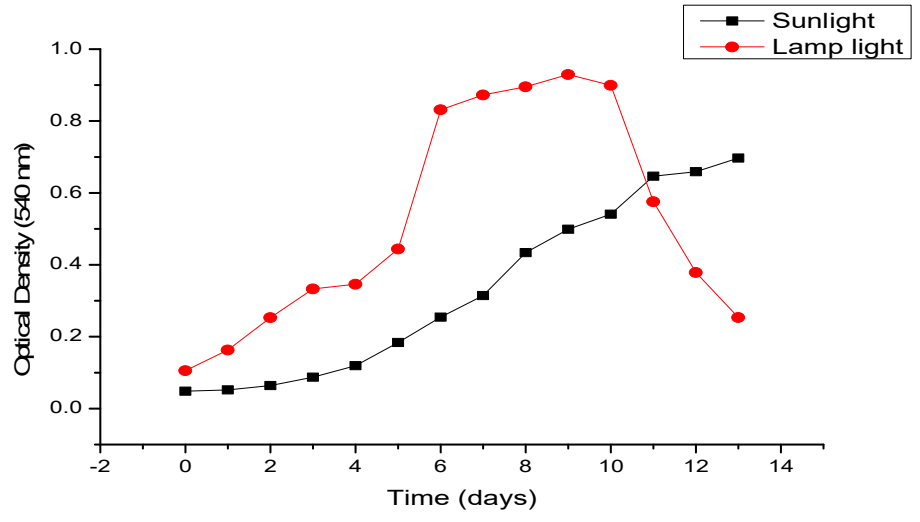

Fig.-3: N. oculata Growth Curve Obtained with Different Light Sources.

Conversely, the exponential phase of culture sourced with sunlight was initiated on day 4, and peaked on the $11^{\text {th }}$ day, with absorbance of 0.65 . Meanwhile, the culture treated with 3000 lux light irradiation exhibited a better growth rate because of the high intensity of light bulb, which is more constant, subsequently elevating the growth rate of $N$. oculata microalgae.

\section{Biomass Estimates}

The relationship between the degree of absorbance and the concentration of biomass $(g / L)$ in the culture medium is known by creating a linear calibration curve line that connects both values.

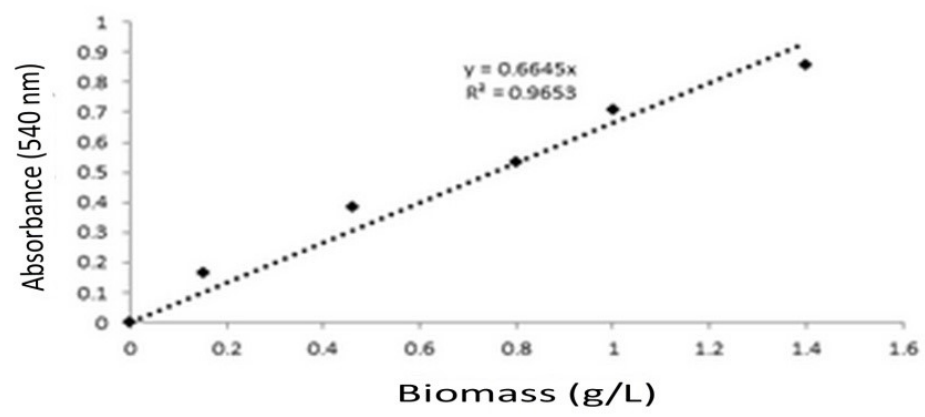

Fig.-4: Calibration Curve relating Optical Density (OD) measured at $540 \mathrm{~nm}$ with Microalgal Dry Weight Biomass.

The above regression equation (Fig.-4) based on the absorbance of 1A denotes the microalgae biomass of $1.5 \mathrm{~g}$, in $1 \mathrm{~L}$ culture. Ward Blanken et al $(2016)^{9}$, suggests the application of the kinetic model in the prediction of growth, because of low accuracy that is due to simplification, and inaccurate parameter estimation in light models. Therefore, specific growth rates were initially estimated with an average absolute percentage (MAPE) of $34-36 \%{ }^{19}$.

\section{Lipid Extraction}

This involved the use of sonicators commonly adopted in the extraction of lipids from microalgae, as the frequency generated tends to break down microalgae cell wall. This technique produced lipid that 
RASĀYAN J. Chem.

Vol. 13 | No. 2 |1134 - 1143| April - June | 2020

dissolves into the hexane solvent due to similarity in polarity yielding $7.2293 \%$ from the dry weight of biomass N. Oculata. ${ }^{13}$

\section{Fatty Acid and FAME Antimicrobial Activity (Escherichia coli)}

Figure-5 showed the enhancement in antibacterial activity of fatty acid and methyl ester fatty acid (FAME) with E. coli at elevated concentrations, which was much lower in contrast with the positive control (streptomycin sulfate). This is because the compounds used have not been purified, and the test results with GC-MS (appendix) showed a mixture of fatty acids and FAME with other compounds ${ }^{16}$.

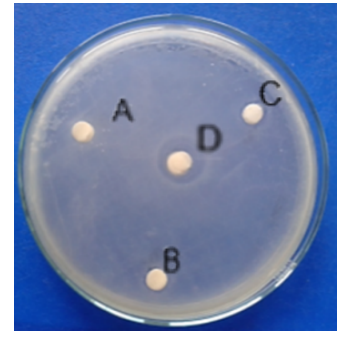

Fatty Acid

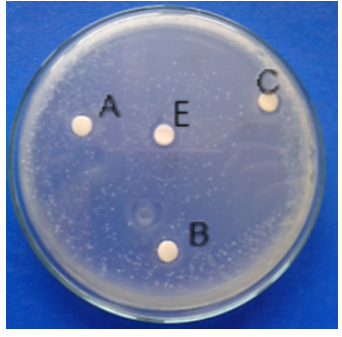

FAME

Fig.-5: Fatty Acid and FAME Antimicrobial Activity (Escherichia coli)

Description: $\mathrm{A}=100 \mathrm{mg} / \mathrm{L}, \mathrm{B}=200 \mathrm{mg} / \mathrm{L}, \mathrm{C}=300 \mathrm{mg} / \mathrm{L}, \mathrm{D}=$ negative control, $\mathrm{E}=$ positive control

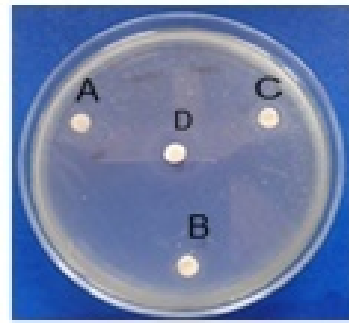

Fatty Acid

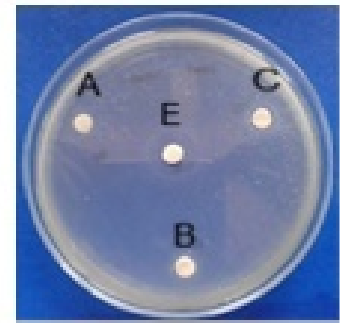

FAME

Fig.-6: Fatty Acid and FAME Antimicrobial Activity (Staphylococcus aureus)

Description: $\mathrm{A}=100 \mathrm{mg} / \mathrm{L}, \mathrm{B}=200 \mathrm{mg} / \mathrm{L}, \mathrm{C}=300 \mathrm{mg} / \mathrm{L}, \mathrm{D}=$ negative control, $\mathrm{E}=$ positive control

Figure- 5 and 6 showed an elevation in the antibacterial activity of fatty acids and methyl ester fatty acids (FAME) against $\mathrm{S}$ aureus bacteria with higher concentrations. However, a comparison with the positive control (streptomycin sulphate) showed much lower activity, due to the presence of impurities. Also, it is possible to identify purity levels from the results of tests with GC-MS that depicts the mixture of fatty acids and FAME with other compounds ${ }^{16}$.

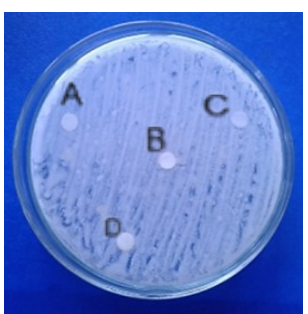

Fatty Acid

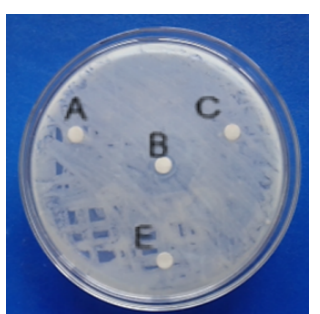

FAME

Fig.-7: Fatty Acid and FAME Antimicrobial Activity (Candida albicans)

Description: A = $100 \mathrm{mg} / \mathrm{L}, \mathrm{B}=200 \mathrm{mg} / \mathrm{L}, \mathrm{C}=300 \mathrm{mg} / \mathrm{L}, \mathrm{D}=$ Negative Control, $\mathrm{E}=$ Positive Control

Figure-7 shows the absence of fatty acids and FAME activities against the only positive control anti-fungi (ketoconazole), which affected Candida ablicans fungus. This is in line with the working mechanism of fatty acids and FAMEs that are unable to control fungi growth.

$$
1140
$$


RASĀYAN J. Chem.

Vol. 13 | No. 2 |1134 - 1143| April - June | 2020

The results in Table II show greater antibacterial activity of $N$. oculata extract of microalgae inoculated with disc diffusion methods, in contrast with other, for both E. coli, and S aureus (in 8 hours). This is indicated by the inhibition zone of $2.55 \mathrm{~mm}$ and 2.855 respectively, as seen in Table-2.

Table 2. Diameter of Clear Zone Fatty Acid and Fame microalgae N. oculata

\begin{tabular}{c|c|c|c|c}
\hline \multicolumn{5}{c}{ Clear Zone Diameter (mm) } \\
\hline Concentration (mg/L) & E.coli & S. aureus & Candida Ablicans \\
\hline Fatty Acid & 100 & 0.595 & 0.745 & - \\
& 200 & 1.680 & 2.630 & - \\
& 300 & 2.550 & 2.855 & - \\
\hline \multirow{2}{*}{ FAME } & 100 & 0.925 & 0.845 & - \\
& 200 & 1.530 & 1.340 & 2.37 \\
\hline \multicolumn{2}{c}{ Positive control } & 2.130 & 1.555 & \\
\hline
\end{tabular}

Table- 2 indicated the antibacterial activity of fatty acid and FAME microalgae $N$. oculata, with no antifungal properties against Candida albicans fungi ${ }^{16}$. Also, gram-positive bacteria were observed to be more sensitive to $N$. oculata microalgae than gram-negative bacteria, which were similar to the report on extracts of Nannochloropsis sp fatty acid, FAME, obtained from Blind Your-Eye mangrove, India, and lipophilic extract from various parts of the Pistacia vera plant ${ }^{16}$. This is due to differences in the cell walls structure of these bacteria, which is simpler for gram-positive species, making it easier for antimicrobial compound penetration. Meanwhile, that of gram-negative cells is relatively more complex, based on the existence of two layers, encompassing the outer lipoprotein and polysaccharide inner film of peptidoglycan. Table 2 also shows the relatively higher sensitivity of gram-negative bacteria to FAME $N$. oculata microalgae that is due to its permeability characteristics ${ }^{16}$. Also, fatty acid-based antibacterial tend to have greater activity than FAME, although both are toxic, based on the presence of surfactants found in cell membranes, and the ability to inhibit protein synthesis. The small clear zone produced by fatty acids and the $N$. oculata microalgae FAME indicates relatively lesser antimicrobial activity.

\section{Analysis of Fatty Acid and Microalgae FAME N. oculata with GC-MS}

The measurement of fatty acid and FAME of microalgae with GC-MS is indicated by the prominent peaks seen in the chromatogram of $7.68 \%$, and $0.94 \%$ respectively, as seen in Tables-3 and 4 .

Table 3. Profile of Fatty Acids from N. Oculata microalgae

\begin{tabular}{c|c|c|c}
\hline $\begin{array}{c}\text { General } \\
\text { Name }\end{array}$ & Chemical Name & $\begin{array}{c}\text { Molecular } \\
\text { Structure }\end{array}$ & $\begin{array}{c}\text { Content } \\
(\%)\end{array}$ \\
\hline $\begin{array}{c}\text { Palmitic } \\
\text { Acid } \\
(\mathrm{C} 16: 0)\end{array}$ & $\begin{array}{c}\text { Hexadecanoic } \\
\text { Acid }\end{array}$ & $\mathrm{C}_{16} \mathrm{H}_{32} \mathrm{O}_{2}$ & 7.68 \\
\hline $\begin{array}{c}\text { Stearic } \\
\text { Acid } \\
(\mathrm{C} 18: 0)\end{array}$ & $\begin{array}{c}\text { Octadecanoic } \\
\text { Acid }\end{array}$ & $\mathrm{C}_{18} \mathrm{H}_{36} \mathrm{O}_{2}$ & 2.14 \\
\hline
\end{tabular}

Table-4: FAME Profile of N. Oculata microalgae

\begin{tabular}{c|c|c|c}
\hline $\begin{array}{c}\text { General } \\
\text { Name }\end{array}$ & Chemical Name & $\begin{array}{c}\text { Molecular } \\
\text { Structure }\end{array}$ & $\begin{array}{c}\text { Content } \\
(\%)\end{array}$ \\
\hline $\begin{array}{c}\text { Methyl } \\
\text { lauric }\end{array}$ & $\begin{array}{c}\text { Methyl } \\
\text { Dodecanoate }\end{array}$ & $\mathrm{C}_{13} \mathrm{H}_{26} \mathrm{O}_{2}$ & 0.94 \\
\hline $\begin{array}{c}\text { Methyl } \\
\text { Stearate }\end{array}$ & $\begin{array}{c}\text { Methyl } \\
\text { Octadecanoate }\end{array}$ & $\mathrm{C}_{19} \mathrm{H}_{38} \mathrm{O}_{2}$ & 0.61 \\
\hline
\end{tabular}

GC-MS analysis shows (Fig.-8) the fatty acid composition dominant in N. oculata was hexadecanoic (palmitic acid) and octadecanoic acid (stearic acid), at 7.68 and $2.14 \%$, respectively. Meanwhile, the minimum inhibitory power of both is relatively low when compared to the value of the positive control 
RASĀYAN J. Chem.

Vol. 13 | No. 2 |1134 - 1143| April - June | 2020

(Streptomycin sulpate). Also, methyl palmitate and methyl stearate where the fatty acid esters (FAME) detected, with a composition of $0.94 \%$ and $0.61 \%$ respectively, with a minimum inhibitory concentration that was not significantly different from the values of the fatty acids. This is due to their mechanism of action in inhibiting bacterial growth, attained by obstructing water, and enzyme systems of some bacteria.

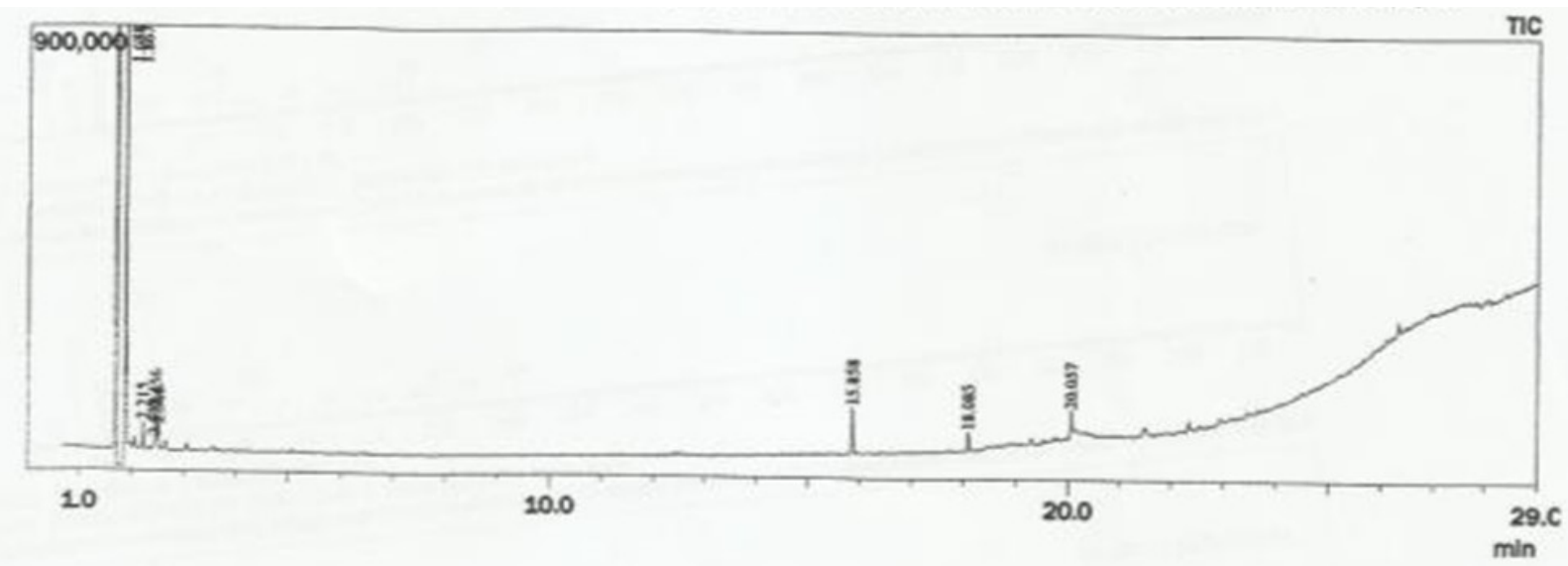

Fig.-8: Chromatogram of Fatty Acid and FAME Antimicrobial Activity (Candida albicans)

\section{CONCLUSION}

From the results obtained, it is concluded that Microalgae $N$. oculata grows better on BBM media, using a light source with an intensity of 3000 lux, and photoperiod of 12 hours each for light and dark. Furthermore, it was established that Fatty acids and FAME present in microalgae $N$. oculata, including palmitic acid, stearic acid, methyl laurate, and methyl stearate ably inhibits the growth of bacteria and not fungi.

\section{REFERENCES}

1. E. Monfet, A. Unc, De Fi Ning, Algal Research, 24, 520(2017), DOI:10.1016/j.algal.2016.12.008

2. P. D. Álvarez-díaz, J. Ruiz, Z. Arbib, J. Barragán,M. C. Garrido-pérez, J. A. Perales, Algal Research, 24, 477(2017), DOI:10.1016/j.algal.2017.02.006

3. M. Bekirogullari, I. S. Fragkopoulos,J. K. Pittman, C.Theodoropoulos, Algal Research, 23, 78(2017), DOI: $10.1016 /$ j.algal.2016.12.015

4. D. M. Ali, R. Praveenkumar,T. Shenbagavali, T. M. Nivetha, Ahamed, P. abdulazees N. A. AlDhabi, N. Thajuddin, Algal Research, 2, 11552(2012), DOI:10.1016/j.algal.2017.06.019

5. M. Jamsa, F. Lyncha, A. Santana-Sanchez, P. Laaksonen, G. Zaitsev, A. Solovchenko, J. Allahverdiyeva, Algal Research, 26, 65(2017), DOI:10.1016/j.algal.2017.06.019

6. M. Castrillo, I. Tejero, Algal Research, 29, 304(2018), DOI:10.1016/j.algal.2017.12.004

7. T. De Mooij, G. D. Vries, C. Latsos, R.H. Wijffels, M. Janssen, Algal Research, 15, 32(2016), DOI: 10.1016/j.algal.2016.01.015

8. P. Pavel, J. Pilný, V. Cepák, P. Ka, Algal Research, 16, 69(2016), DOI:10.1007/s10811-019-1738-9

9. W. Blanken, P.R. Postma, L. D. Winter, R. H. Wijffels, M. Janssen, Algal Research, 14, 28(2016), DOI: $10.1002 /$ btpr.379

10. M. Huesemann, B. Crowe, B. Waller, A. Chavis, S. A. Hobbs, Algal Research, 13, 195(2016), DOI: 10.1016/j.algal.2016.11.016

11. A. Maria, P. Neto, R. Augusto, S. Souza, S. De, A.D. Leon-nino, D. Joana, T. Sbrolini, T. Abreu, T. Cristina, S. Mello, Renew Energy, 55, 525(2013), DOI:10.1016/j.renene.2013.01.019.

12. H. Shin, J. Ryu, S. Bae, C. Crofcheck, M. Crocker, Fuel, 3, 21(2014), DOI:10.1007/s12257-0170392-9

13. A. Silve, I. Papachristou, R. Wüstner, R. Sträßner, M. Schirmer, K. Leber, B. Guo, L. Interrante, C. Posten, W. Frey, Algal Research, 29, 212(2018), DOI:10.1016/j.algal.2017.11.016

14. K. Silas, H. B. Kwaji, B. Gutti, International Journal of Recent Research in Physics and Chemical 
RASĀYAN J. Chem.

Vol. 13 | No. 2 |1134 - 1143| April - June | 2020

Sciences, 2, 26(2015).

15. B. Özçelik, M. Aslan, I. Orhan, T. Karaoglu, Microbiology Reserach., 160, 159(2005).

16. M.E. Arias, J.D. Gomez, N.M. Cudmani, M.A. Vattuone, M.I. Isla, ex Hook Arn., 5, 191(2004).

17. Kawaroe, M. Partono, T. Sunudin, D.S. Wulan, dan D. Augustine, Microalgae: Their Potential and Utilization for the Production of Bio Fuels, IPB Press, Bogor, (2010).

18. B. Dallaire, N. Bernet, and O. Bernard, Journal of Biotechnology Advances, 27, 409(2007).

19. B.R. Saputro, E. Kusdiyantini, H.P. Kusumaningrum. J. Biologi Sains, 4, 15(2015).

20. Kawaroe, M. Pratono, T. Sunuddin, A. Sari, and D. Augustine, Indonesian Journal of Fisheries and Fisheries Sciences, 16, 73(2009).

21. S.P. Ceullar-Bermudez, M.A. Romero-Ogawa, R. Vannela,Y.S. Lai, B.E. Rittman, R. Parra-Saldivar, Algal Research, 12, 10(2015), DOI:10.1016/j.jpowsour.2015.03.097

[RJC-5677/2019] 